\title{
O USO DO TERRITÓRIO PAULISTANO PELO HIP HOP: A TEORIA DE MILTON SANTOS PARA A COMPREENSÃO DA FORÇA DO LUGAR*
}

\author{
Carin Carrer Gomes
}

Resumo: Entre os usos informacionais e corporativos de São Paulo e suas fragmentações engendra-se, desde a década de 1980, o movimento Hip Hop, o qual traz à tona novos usos dos objetos e ações que configuram São Paulo. Assim, as investigações aqui apresentadas buscam compreender como um território cada vez mais preparado às ações de interesses capitalistas abriga e fortalece a prática do movimento Hip Hop. Este movimento funde relações territoriais corporativas à escassez produzida em seus locais, valorizando e veiculando a consciência dos usos do território pelo lugar e pela cultura.

Palavras-chave: território paulistano, paisagem, cotidiano, lugar, Hip Hop.

\section{USE OF SÃO PAULO TERRITORY BY HIP HOP: THE THEORY OF MILTON SANTOS TO UNDERSTAND THE POWER OF PLACE}

\begin{abstract}
Among the informational and corporative uses of São Paulo city and also its fragmentations, the Hip Hop movement emerged in 1980s brings new possibilities of using objects and actions that form the São Paulo city. Therefore, in the scrutiny here presented we sought to comprehend how a territory prepared to the capitalist interests hold and strengthen the emergence of movements such as the Hip Hop that favors the fusion of territorial corporative relationships to the shortage produced in those places, valuating and casting the conscience of using the territory by the place and culture.
\end{abstract}

Keywords: "Paulistano" territory, landscape, daily, place, Hip Hop.

\section{Introdução}

Entrei pelo seu rádio, tomei, você nem viu...

Racionais MC'S, 2002

O objetivo mais esperado em nosso trabalho foi compreender como o espaço se impõe a tudo e a todos, como contingência e possibilidade. Essa compreensão é a obra de Milton Santos em nosso mestrado.

Importante também expormos que o resultado da Dissertação, segundo Maria Adélia de Souza, é o processo de formação disciplinar e de pesquisa. Ou seja, dissertar um tema, é exercitar o conhecimento de um dado recorte do objeto à luz de uma teoria de uma dada disciplina. Assim, o maior resultado, foi o esforço no uso da teoria da Geografia Nova como processo mental, aproximando-nos das realidades espaciais.

Nesse trajeto encontramos no território paulistano, por um processo de usos fragmentados, o movimento Hip Hop, foi nessa perspectiva que vislumbramos 0 exercício da Geografia Nova pelo movimento territorial do Hip Hop. Desse encontro partiu nossas análises sobre um possível uso do território paulistano pelo Hip Hop.

\footnotetext{
* Artigo elaborado a partir da dissertação $O$ uso do território paulistano pelo Hip Hop, orientada pela $\operatorname{Prof}^{\mathrm{a}} \mathrm{Dr}^{\mathrm{a}}$ Maria Adélia de Souza, do Programa de Pós-graduação de Geografia Humana da Faculdade de Filosofia, Letras e Ciências Humanas, Universidade de São Paulo, e defendida em 2008.
} 
É imprescindível situar que nosso mestrado é parte das pesquisas sobre as desigualdades e injustiças socioespaciais brasileiras orientadas por Maria Adélia de Souza. Para essa geógrafa, a obra de Milton Santos é fundamento na compreensão das realidades expressas na formação desigual e apartada da justiça nos usos do território brasileiro, mas é também, por isso, meio para resistências.

A visão crítica de mundo que o conhecimento dessa obra nos permite, em específico o livro "Por uma outra globalização: Do pensamento único à consciência universal", guiou a estrutura da nossa dissertação. Milton Santos, nesse livro, nos alerta para o fato de que a globalização, é, num só momento, uma fábula, uma perversidade e uma possibilidade para os lugares. Portanto, nosso relato expõe o quanto o cotidiano globalizado e seletivo cria, no território paulistano, perversidades em fragmentos do território e, ao mesmo tempo, forja configurações que se impõem para que agentes criem sua arte e suas solidariedades.

$$
\text { Ora, o Hip Hop, segundo nossa }
$$
pesquisa, existe exatamente no período em que São Paulo vai preparando-se para as modernizações cuja finalidade é tornar-se função do capital financeiro. Não nos deteremos aqui a essa discussão, pois já é amplamente discutida nos demais artigos dessa edição especial da GEOUSP. O mais instigante da obra de Milton Santos é que no decorrer das nossas investigações não pudemos desconsiderar outras pesquisas, e a diversidade de recortes, para a compreensão dos usos do território de São Paulo.

Apartados dessa visão geográfica, descreveríamos as paisagens por meio do senso comum - por exemplo, senso advindo da psicoesfera formada pela mídia, cujo alcance, levar-nos-ia por um lado a não enxergar e reconhecer outros usos territoriais, ou outros lugares que não aqueles dos interesses das redes informacionais ou, por outro, vislumbraríamos essas paisagens numa criminalização do uso territorial pelo Hip Hop, sem a devida problematização que o espaço se impõe e por isso é legítimo para todos os seus agentes.

Portanto enxergar as paisagens do Hip Hop, primeiro capítulo da nossa dissertação, foi um exercício de reconhecer que existe um cotidiano paulistano, nos interstícios das redes, que utiliza do rap, do break (a dança) e do grafitti (a arte gráfica) para fazer arte, onde o território não se configura para tal. Nesse processo artístico denuncia sua impossibilidade de existir no território fragmentado, o que lhe é peculiar.

$$
[\ldots]
$$

Artistas de um mundo que não existe, é música de ladrão, de um mundo que não existe, a discriminação, de um mundo que não existe artistas ou não, artistas de um mundo que não existe sem consagração, de um mundo que não existe, um sonho todo em vão, de um mundo que não existe artistas ou não. [...] (Facção Central, 1995).

\section{Um movimento territorial: os quatro elementos do Hip Hop}

O movimento Hip Hop é um dos expressivos usos do território paulistano no presente. As suas artes constituem paisagens por todos os lugares de São Paulo, as quais 
nos trazem as primeiras incitações sobre possibilidade de ação em um território constituinte de desigualdades.

Os quatro elementos que compõem o Hip Hop podem ser compreendidos por seus elementos artísticos territorializados, ou seja, pelo break, pelo grafitti, pelo $m c$ e pelo $d j$. 0 Hip Hop, em seus quatro elementos, associase às ações possíveis e estas estão indissociadas do território. A prática do movimento passa ao domínio da Geografia em seu uso territorial, o que implica objetos e ações engendrando lugares.

O break parte da arte da dança por meio das possibilidades assimilando, produzindo e circulando essa cultura nos locais mais carentes. Tem sua origem na cultura norte-americana que se "internacionalizou" e instalou-se, primeiramente, nas grandes capitais do mundo. Os movimentos do break são subversivos, pois carregam em sua forma todo o conteúdo histórico e presente do estado do mundo com o estado do seu lugar. Carrega, nos gestos artísticos, a história da intenção de desviar os conflitos de "gangues" de diferentes locais, em um contexto territorial próprio norte-americano, para as batalhas de break.

Esse elemento que compõe o movimento Hip Hop, dançado pelos b. boys e b. girls, traz o cotidiano da dança de rua como possibilidade de arte, construindo atuais possibilidades de usos das configurações territoriais em sua produção, apresentação e organização de "batalhas" em diversas solidariedades. Batalhas num primeiro momento orgânicas às possibilidades dos locais e recentemente organizacionais por meio de grandes eventos e de patrocínios. Solidariedade empresarial que possibilitou uma visibilidade nos grandes meios de produção e divulgação na racionalidade de competições esportivas e artísticas, recebendo investimentos de diversas instituições para os campeonatos que são, atualmente, a formalização da dança de rua pelos usos do território. Por exemplo, o Campeonato Mundial de B.Boy patrocinado pela empresa Red Bull ocorrido no Memorial da América Latina do município de São Paulo no ano de 2006.

Aqui temos uma apreensão das promoções entre instituições privadas (no caso, a empresa Red Bull) e a dança. É uma situação cada vez mais recorrente no uso de políticas e ações, associando aos investimentos culturais os interesses empresariais, que acaba lhes rendendo propaganda que associam a arte ao seu produto e também isenções fiscais. $E$, nesse sentido, o Hip Hop, no caso o break, tem sido usado por essa recente política empresarial ao mesmo tempo em que o break aproveita para dar continuidade ao seu movimento.

Muitas vezes o grafitti está também na pauta de políticas culturais, reservando a alguns locais a aprovação de projetos, ora de secretarias e coordenadorias do poder público municipal, ora com parcerias entre escolas, Ong's e instituições privadas.

No entanto, em diversos locais de São Paulo, o grafitti é um uso do território que vive na "ilegalidade", junto aos usos do território pelas pichações. Seus locais não são escolhidos pela formalização dos usos e, na maioria, não participam de projetos culturais; as escolhas dos usos partem dos princípios dos próprios grafiteiros e, com a formação e informação, advinda também com o 
movimento Hip Hop, o grafitti passa a ser uso que propõe arte praticada pelos muros e paredes do território paulistano.

As práticas do grafitti são usos do território que mostram a velocidade do período histórico em que vivemos, arte que se faz rapidamente e desfaz-se também, trazendo novas práticas para pensarmos sobre a importância do debate territorial acerca da arte que, para o grafitti, está muito mais na ação, no conteúdo exposto e nos possíveis usos do território, do que na própria duração e na formalidade de exposição.

O grafitti é umas das paisagens mais visíveis do uso do território, não há um lugar no território paulistano de que este elemento não tenha sido parte, em algum momento, da paisagem, com sua arte impressa nos muros. A escassez, aqui também de estruturas e ações para o desenvolvimento desse elemento, engendrou sua formaconteúdo: estar nos muros, estar pelas ruas, pelas técnicas de sua pintura, com sua conotação subversiva confere-lhe um uso específico do território, uma proposição de arte nas paredes das ruas da cidade. Os materiais e conteúdos do grafitti são também usos que foram historicamente se dando: a prática de paredes, ao invés de telas, de latas de látex e depois de sprays de tintas ao invés de tradicionais objetos de pintura, remonta o saber fazer pelas condições desiguais e possibilidades situadas e criativas.

O Mc, ou mesmo o rapper, o cantor de rap, produz versos sobre o cotidiano do território, a técnica do Mc está associada diretamente ao conteúdo e forma do local; a linguagem, como comunicação, está intrinsecamente associada ao processo de uso do território: no que diz e como diz, o Mc é o relato, conhecimento e comunicação do seu lugar pelo canto e pela fala. O rap - pelos $M c^{\prime} s$ e $D j$ 's - é uma técnica de discurso contundente sobre, muitas vezes, a desigualdade territorial. Nessas músicas estão declarados o território e suas desiguais possibilidades. Como vemos neste trecho da letra Negro Drama, "Eu recebi seu ticket, quer dizer kit, de esgoto a céu aberto $e$ parede madeirite, de vergonha eu não morri, tô firmão, eis-me aqui" (Racionais MC'S, 2002).

O DJ fez dos objetos eletroeletrônicos e das tecnologias informacionais instrumentos para a construção de bases musicais, para tanto, criou também o sample (cópia de trechos de músicas existentes). Rearranja sonoridades pelas limitadas condições e que, concomitantemente, foi transformando em música, em estilo. Como o manuseio no par de pick-ups (toca discos), que rende ao mundo novos usos das bases musicais, por exemplo, as batidas e os famosos scratchs (intervenção na rotação do disco criando efeitos de "arranhadura"), a marca dos Djs do Hip Hop. Utiliza-se, ainda, de softwares para produzir suas bases. Detêm um conhecimento criativo, primeiramente, fora das formalidades e dos conteúdos centralizadores da produção musical; porém, vão apreendendo com fragmentos as novidades do mundo $e$ transformando em música uma materialidade dada.

O cotidiano é a dimensão geográfica flagrada pelas paisagens em que o Hip Hop vai ser composto e compor o território. Cotidiano é o conceito central na nossa Dissertação, pois qualifica as razões híbridas expressas nos lugares e nos usos do território; é a dimensão do encontro 
contraditório entre as razões globalitárias (SANTOS, 2000) e as verdadeiras razões locais.

\section{Configurações territoriais: contingências para o uso}

O movimento Hip Hop estrutura-se em São Paulo concomitantemente ao fortalecimento do processo do período informacional na década de 80 e segue na década de 90. Reafirmamos a relação entre São Paulo informacional e a formação do movimento Hip Hop paulistano na medida em que a história do movimento está completamente associada às configurações territoriais de cada momento na formação do território.

Na década de 1980, a maior parte da população paulistana morava longe dos centros em que muitos trabalhavam; tanto o velho centro paulistano, ou mesmo a região da Avenida Paulista, eram lugares de passagem e serviços para muitos jovens. $\mathrm{Na}$ prestação de serviço, na busca de emprego, ou no estudo, o centro passou a ser para eles o lugar em que se iniciaram os encontros do que viria a ser o Hip Hop paulistano.

Importante notar que esses espaços públicos centrais usados por esse movimento eram locais dos equipamentos mais modernos paulistanos da época: a estação de metrô São Bento, a Praça Roosevelt e a Galeria 24 de maio.

O centro de São Paulo foi o lugar de início do encontro dos primeiros passos de break; o conhecimento da dança chegou nos bailes blacks que haviam em São Paulo, nos primeiros filmes e nos videoclipes, substanciando, assim, a formação de ensaios e apresentações primeiramente em frente ao Teatro Municipal, na Praça Ramos e, logo depois, no cruzamento da Rua 24 de Maio com a Rua Dom José de Barros. Neste último local encontravam-se duas grandes pedras de mármore no chão, ideais para os passos que delineavam o break paulistano. O som advindo do "box" (radiogravador de grande porte) e do "beat box" (improvisação pela boca do som da bateria, do baixo e de outros instrumentos).

Nesse momento a Galeria 24 de Maio afirma-se como encontro da cultura black, ela terá, desde os primeiros momentos, músicas e artigos relacionados ao Hip Hop, constituindo fundamental mercado de produtos e tornando-se importante encontro dos Hip Hoppers, por passar a ser, também, local de informação sobre os circuitos que o movimento criará no território paulistano.

Com a modernização da estação São Bento, em 1975, esta passou a ser importante nó da rede de transporte metroviário. Na década de 80 é símbolo das modernizações de fluxo que São Paulo acolhe. Esse local é outro marco histórico do Hip Hop paulistano. Foi ali também que os primeiros Mc's rimaram com improvisados sons de batidas de latas de lixo, de palmas, ou mesmo, de "beat-box". Multiplicam-se, ali, as crews de break (grupos de break) dando corpo às batalhas, dando o sentido às disputas que animam as apresentações desse elemento.

E é em 1988 que o Hip Hop brasileiro tem seu primeiro rap "oficial" na indústria fonográfica, produzindo seu primeiro disco, a coletânea "Hip Hop cultura de Rua", pela gravadora Eldorado, cuja capa do disco tem 
como imagem a Estação São Bento e os artistas da coletânea.

A Praça Roosevelt, localizada na região central paulistana (no bairro da Bela Vista), inaugurada na década de 1970 como um moderno ponto paulistano, principalmente pelo seu projeto arquitetônico de praça suspensa, foi um dos locais importantes na organização do Hip Hop. Em 1989, na heterogeneidade dos hip hoppers na São Bento, alguns, principalmente rappers, buscaram nessa praça realizar seus encontros.

Nesse cotidiano, entre a Galeria 24 de Maio, a São Bento e a Praça Roosevelt, foi-se criando um circuito horizontal pelo território paulistano. Esse circuito solidarizou, cada vez mais, informações das formas e conteúdos intrínsecos e possíveis a todo o movimento, por todo o território paulistano.

\section{As técnicas da informação: flexibilização, circuitos e solidariedades}

Para compreendermos qualquer ação do Hip Hop devemos apreender o estado da técnica do período, não só por seus objetos técnicos materiais, mas, também, pelo uso que se encontra no território: A produção do $D J$, bem como a produção do $M c$, tornam-se mais concretas com os objetos técnicos informacionais (por meio da flexibilização pelos usos), criam-se circuitos "improvisados" para a produção de rap. Antes essas bases técnicas só eram disponíveis para as grandes gravadoras, e, agora, com a expansão do meio técnico-científico e informacional e com alguns equipamentos mais acessíveis pode-se montar um pequeno estúdio de gravação em locais nos quais ele era inimaginável. Com isso, o território abriga novos lugares, por novas organizações de produção de música, criando circuitos produtivos.

Esses circuitos foram apreendidos também na pesquisa do geógrafo Cristiano Nunes Alves (2005), que, ao tratar da atual Região Metropolitana de Campinas, vai construir uma detalhada pesquisa sobre a criação de um circuito do Hip Hop metropolitano, afim não só com o Hip Hop, mas com os imperativos territoriais. E outra pesquisa geográfica relevante às reflexões sobre um possível circuito territorial que o Hip Hop instala mediante as solidariedades territoriais existentes é a Dissertação de mestrado da geógrafa Denise Prates Xavier (2005).

Uma importante ferramenta nesse universo da produção musical de rap, advinda da informática, deu-se por meio das inovações tecnológicas com os diversos softwares, programas que substituem alguns processos das produções musicais. Mesmo com o acesso aos softwares restritos pelos altos preços, o programa 'pirateado' foi uma "flexibilização" ao acesso, ainda que obediente ao circuito superior da produção. Nas ruas de São Paulo, nos centros comerciais e, nas ruas especializadas de instrumentos musicais e diversos tipos de eletroeletrônicos, como na Rua Santa Efigênia no centro de São Paulo, encontramse diversos circuitos da economia inferior que vendem esses programas para computador por baixo custo, possibilitando mais acesso aos $D j$ 's, ou grupos de rap, para a produção de suas músicas. Todavia, como há nessa possibilidade do software um conjunto técnico que Ihe aciona o uso, as sofisticações técnicas informacionais é, para tanto, um conjunto de objetos que não é de acesso 
imediato a toda população de São Paulo reafirmando sempre o caráter improvisado da produção.

A produção (propriamente dita) do projeto de um álbum até o processo de transformá-lo em mercadoria, como CD, DVD e mesmo os vinis (geralmente como instrumento aos DJs) e, depois, a sua colocação para a circulação, a distribuição e o consumo, perpassa por um complexo circuito entre as gravadoras ou os selos que dirigem toda ou grande parte do projeto até a mercadoria que, com o projeto escolhido, passa para a produção em estúdio, depois materializado na Zona Franca de Manaus (a prensagem), passando, também, pela produção da arte gráfica dos encartes para, finalmente, virar mercadoria para ser distribuída e comercializada. Processo constrangedor, muitas vezes, para um projeto artístico que não detêm tal comando, pela impossibilidade de acessar todo o circuito de produção.

A maior parte dos gêneros musicais tem esse circuito como norma de ação à produção de suas obras e, esse circuito, cada vez mais, restringe-se às grandes empresas centralizadoras no comando de todo o processo, uma vez que detêm as possibilidades econômicas, políticas, culturais e, principalmente, informacionais do território. Essas organizações empresariais possuem os meios informacionais da produção para se articularem no território paulistano, ou em outros territórios, afins com o circuito produtivo, por exemplo, de um CD. Com isso, impõe-se ao universo da música um monopólio da produção. Cada vez mais as grandes gravadoras organizam-se para a centralização do comando e a descentralização dos processos de produção (pelas cooperações que organizam pelo território).

O sucesso dessas poucas e centralizadoras empresas está, também, na solidariedade organizacional com a grande mídia (rádio, TV e outros meios de comunicação), bem como coincide com os projetos político-culturais governamentais, assim criando um verdadeiro circuito de organização, produção, circulação, regulação e, como fim, criando o que se deve consumir nos lugares, com comércios cada vez mais padronizados, bem como no circuito inferior, impondo o produto a ser copiado, distribuído e, mesmo, pela comercialização na Internet.

No circuito superior, as escolhas dos projetos musicais não contemplam todas as culturas de um território. Sua racionalidade é econômica, e, assim, sua produção sobrepõese às culturas dos lugares. A música rap só passa a ser interessante para esse circuito a partir do momento em que a mesma lhe gera lucros e obediências; caso contrário, o interesse desse circuito ao que é projeto de música ao movimento Hip Hop não está incluído nos projetos das grandes empresas.

Como contra racionalidade 0 movimento passa a compor em suas possibilidades técnicas e nas suas possibilidades de ações modos de produzir que são uma adaptação desse circuito superior ao qual não lhe é possível pertencer em todo o processo. Muitos grupos do Hip Hop, a partir da década de 90, veem na criação de pequenos estúdios (ou no uso de pequenos já existentes), pequenas gravadoras, ou pequenos selos (os chamados "independentes"), uma oportunidade de criar partes das etapas do processo de produção já que não podem, ou se recusam, a participar 
de todas as possibilidades do circuito superior.

Quanto à criação de pequenos selos e pequenas gravadoras, para o processo produtivo, a maioria destas lançava álbuns e tinha como problema a circulação da mercadoria, em sua distribuição e comercialização (lugares para a venda, bem como o uso das mídias para a divulgação). Com tal prática, os rappers percebem que o problema não é pontual, de falta de condições materiais à produção: percebem que há um circuito territorial de produçãocirculação que não lhe é acessível e está, no território paulistano, completamente centralizado em grandes circuitos do processo já descrito. Ao mesmo tempo em que produzem em pequenas gravadoras e selos (possível também pela flexibilidade técnica que já desenvolvemos), dependem das estruturas de circulação, distribuição e consumo territorializados.

A Internet passa a ser, então, importante meio para a produção e comunicação do rap. Assim, um dos meios empregados pelo Hip Hop advém hoje dos aparatos técnicos que sites disponibilizam, muitos "gratuitamente", como bases de produção, organização, comunicação e divulgação. Como o caso do álbum do grupo de rap da zona norte de São Paulo, CAGÊBE:

Imagem do álbum Lado beco

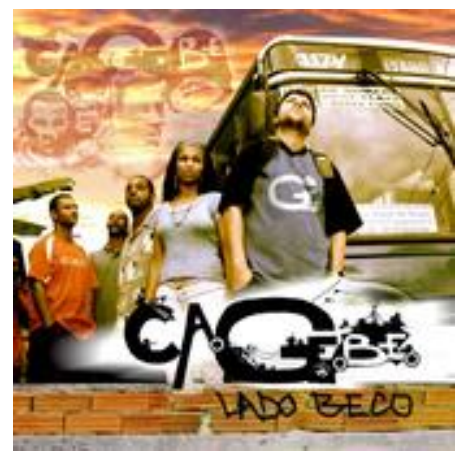

Imagem do álbum Lado beco (CAGÊBE, 2006), exposto no site Myspace.
Por meio do site Myspace (que congrega comunicação, informação e música de qualquer grupo que queira se cadastrar) possibilita que o processo de criação, produção e mesmo a circulação exponha as condições do lugar do grupo. Segundo o release do grupo:

Lado Beco é o álbum de estreia do grupo
de rap CA.GE.BE, formado na zona norte
de São Paulo, há 6 anos. CA.GE.BE, sigla
para "cada gênio do beco", conta com a
produção do DJ QAP do SP Funk nesse
primeiro trabalho. Ao contrário da maioria
dos músicos do Hip Hop, o grupo utiliza
elementos de sons considerados pelo
público em geral como brega. Gente como
Barros de Alencar, Aguinaldo Timóteo e
Altemar Dutra são constantemente citados
pelos integrantes. Os rappers do CA.GE.BÊ
cresceram escutando rádio AM, "Vem daí a
nossa identidade com esse tipo de
música". A gravação do álbum de estreia
do CA.GE.BÊ começou na garagem da
casa do DJ QAP. "A gente tinha que
esperar os carros passarem na rua pra
rimar", explica o MC André. ${ }^{1}$

Esses sites de comunicação, como no caso do myspace, são elaborados e disponibilizados pelos circuitos da grande mídia "gratuitamente"; em contrapartida utilizam-se dessa demanda de usos, como do rap, que não tem, na maioria das vezes, acesso às tradicionais mídias (como as grandes rádios, a TV e outros meios de comunicação) como banco de dados e possíveis meios para o mercado da propaganda. A Internet, que é cada vez mais parte do território paulistano, pelos investimentos cada vez maiores em tecnologias da informação e comunicação, mesmo que seletivos e rígidos à específicos usos, ainda assim, passa a ser uma forma a mais para a instrumentalização de todos os processos de comunicação do Hip Hop.

\footnotetext{
1 Site de divulgação Myspace. Disponível em: <http://www.myspace.com/cagebe/>. Acesso em: dez. 2007.
} 
Essa foi a natureza contraditória do território paulistano e foi também a razão considerada indissociada da emoção dos lugares em que o movimento forja cotidianamente sua prática que vislumbramos com a teoria miltoniana. Se a informação é um dado, cada vez mais, de valoração territorial para poucos, por outro lado é, mesmo de forma restrita, base para a comunicação de muitos. Esta é a articulação para os usos não previstos (pela razão dominante), forjada nos locais, é a resposta ao descaso e a razão cotidiana dos que ali coexistem.

\section{Lugar e informação: motores para a comunicação popular}

Se a pesquisa que apresentamos em nosso mestrado dimensiona a paisagem, o cotidiano, o passado e o presente uso do território paulistano por meio de categorias que racionalmente apreendem o movimento Hip Hop como prática também de um mundo hegemonizante, a categoria lugar, que nos instrumentalizou para acessar a qualidade dos usos, redimensionada no período atual pela obra de Milton Santos, em sua dimensão comunicacional fortaleceu nossa compreensão dos novos usos, na medida em que a prática territorial revela o movimento como sinônimo de lugar, de economia e de política.

Assim, o Hip Hop tem como força de movimento a relação entre os seus lugares e o território informacional praticado pela comunicação que estes criam, pois no território entre fragmentos e usos corporativos dos locais ascende, nessas contradições, a consciência do território pela comunicação do Hip Hop. A força está alicerçada no encontro das faltas nos usos e no futuro imediato comunicado conformando seus lugares.

$$
\text { O lugar, então, constitui-se como }
$$
condição espacial da resistência, da razão da vida popular em sua escassez e da proposição de uma nova racionalidade que conduz a uma nova política. Para Milton Santos (2000), em entrevista:

Os compositores de música popular resistiram à massificação da música e hoje conseguem levar suas ideias à população. Existem músicos, como o Mano Brown, que não estão nas grandes gravadoras e que conseguem vender de forma significativa. (FARIA; GANANIAN, 2007).

Cada lugar impõe suas pretensões, que não são as mesmas da hegemonia, pois mesmo que esta esteja fortemente e verticalmente presente no território, ela não liquida as pretensões horizontais dos mesmos. Milton Santos propôs que pensemos, pelas mesmas bases técnicas do período, que coexiste uma outra globalização, como possibilidade, que está nos interstícios da razão hegemônica e desprezada muitas vezes pelos projetos do próprio território paulistano.

Se o trunfo da difusão das grandes corporações financeiras é a informacionalização como uso do território, o do Hip Hop é a comunicação, base da atividade dos seus quatro elementos, que garante a difusão da informação. Já a informatização para usos globalizantes no território é muito mais para a seletividade da ação do que mesmo a informação comunicada para todos.

A comunicação transforma o emissor e o receptor em um lugar comum. Temos no 
Hip Hop um esforço e a necessidade de não dissociação desses pares para a sua continuidade. Seu lugar produtivo não é uma funcionalidade exclusiva de energia, ou de informação sem ação, e é pela comunicação que esse processo não se perde de produção e informação.

O interesse do $M c$ é a comunicação pela fala, pela palavra; sua necessidade de comunicação com o outro se transforma também com as mudanças do meio, criando um novo ambiente comunicativo pelas possibilidades técnicas e pelos usos do território. Seu instrumento imediato é o discurso, seus temas são, em sua maioria, o cotidiano, e seu interlocutor é o seu próximo.

A importância da comunicação está na consolidação da fala e da recepção através do uso dos meios para comunicar-se; porém, - meio define as possibilidades de comunicação desde que a comunicação faça sentido para a circunstância comunicada; portanto, a ação de comunicar depende não só do meio, mas também das circunstâncias (do receptor); assim, a ação se consolida através da intercomunicação entre comunicado e comunicante. Para tanto, os MCs estão ancorados na comunicação do seu local, e também ancorados nos objetos e ações informacionais como instrumento da sua atividade.

O graffiti, neste período da
velocidade, tem sua razão em todo o
território - arte em que não importa a
duração e sim a ação e o uso do território -,
comunica-se instantaneamente com o lugar
que vai conformando às suas marcas. Sua
circulação é a totalidade da cidade,
principalmente paredes e muros pelas ruas,

instalando, contraditoriamente, uma nova razão à existência de muros e paredes.

A razão do Hip Hop está alicerçada nos lugares que criam como encontro de consciência e de fazer, junto ao mundo como é: nascido de uma difusão técnica capitalista (qualquer objeto técnico do Hip Hop - no uso pelos elementos que o constitui - é um objeto difundido pela intenção do mundo capitalista), ainda assim, sua organização e seu uso não são os mesmos do capital hegemônico.

A tomada de consciência do Hip Hop perpassa pelo mundo tal como se apresenta, ou seja, desigual, e como se apresenta no mentiroso discurso, oportunidade a todos. Mas passando, também, pelo mundo como possibilidade de outros usos constituindo outros lugares.

O movimento territorial do Hip Hop instala, assim, atividades populares sobre os locais de São Paulo; seu valor é o homem, o seu próximo e a sua cultura territorializada, impondo, cada vez mais, um debate consciente e comunicativo pela arte em sua escassez perante a abundância informacional dos usos massificantes. A obra de Milton Santos é compreensão e revelação da força do lugar:

No fundo, a questão da escassez aparece outra vez como central. Os "de baixo" não dispõem de meios (materiais e outros) para participar plenamente da cultura moderna de massas. Mas sua cultura, por ser baseada no território, no trabalho e no cotidiano, ganha a força necessária para deformar, ali mesmo, o impacto da cultura de massas. Gente junta cultura e, paralelamente, cria uma economia territorializada, uma cultura territorializada, um discurso territorializado, uma política territorializada. Essa cultura da vizinhança valoriza, ao mesmo 
tempo, a experiência da escassez e a experiência da convivência e da solidariedade. É desse modo que, gerada de dentro, essa cultura endógena impõe-se como um alimento da política dos pobres, que se dá independentemente e acima dos partidos e das organizações. Tal cultura realiza-se segundo níveis mais baixos de técnica, de capital e de organização, daí suas formas típicas de criação. Isto seria, aparentemente, uma fraqueza, mas na realidade é uma força, já que se realiza, desse modo, uma integração orgânica com o território dos pobres e o seu conteúdo humano. Daí a expressividade dos seus símbolos, manifestados na fala, na música e na riqueza das formas de intercurso e solidariedade entre as pessoas. $\mathrm{E}$ tudo isso evolui de modo inseparável, o que assegura a permanência do movimento. [...] os símbolos "de baixo", produtos da cultura popular, são portadores da verdade da existência e reveladores do próprio movimento da sociedade (SANTOS, 2000, p. 143-145).

Como relatamos o movimento é contingência da escassez e, no mesmo processo, arte dos interstícios do meio geográfico atual. Seu engajamento, como movimento social, é, simplesmente, ser arte em usos não previstos, portadora de outras existências.

\section{Referências bibliográficas}

ALVES, C. N. O circuito Hip Hop na região metropolitana de Campinas: para que o território e a arte digam algo sobre nossas vidas. Trabalho de Conclusão de Curso (Graduação em Geografia) - Departamento de Geografia, Instituto de Geociências, Universidade de Campinas, Campinas, 2005.

ANDRADE, E. N. (Org.). Rap e educação: rap é educação. São Paulo: Summus, 1999.

FARIA, G.; GANANIAN, J. O novo não se inventa, descobre-se. Entrevista com Milton Santos (2000). Revista Fórum, nov. 2007.

GOMES, C. C. Conhecer o lugar e transformar o mundo: O espaço geográfico como possibilidade. In: SOUZA, M. A. (Org.). Território brasileiro: usos e abusos. Campinas: Territorial, 2003.

MARQUES, E. R. C. Para além dos quilombolas urbanos: Hip Hop, o movimento social urbano que possibilita transformar territórios através de ação política e arte. Trabalho de Conclusão de Curso (Graduação em Geografia) Pontifícia Universidade Católica de Campinas, Campinas, 2006.
ROSE, T. Um estilo que ninguém segura: política, estilo e a cidade no Hip Hop. In: HERSCHMANN, M. Abalando os anos 90. Rio de Janeiro: Rocco. 1997.

SANTOS, M. O espaço do cidadão. 4. ed. São Paulo: Nobel, 1998.

. Metrópole corporativa e fragmentada: o caso de São Paulo. São Paulo: Nobel,

Por uma outra globalização: do pensamento único à consciência universal. São Paulo: Record, 2000.

SCANDIUCCI, G. O lugar do Hip Hop em São Paulo e os desenhos grafitados como marcas das periferias. In: POATO, $\mathrm{S}$. et al. (Orgs.). Graffiti na cidade de São Paulo e sua vertente no Brasil. São Paulo: DPL, 2006.

SILVA, A. B. A contemporaneidade de São Paulo: produção de informações e novo uso do território brasileiro". Tese (Doutorado em Geografia) Faculdade de Filosofia, Letras e Ciências Humanas, Universidade de São Paulo, São Paulo, 2001.

SOUZA, M. A. A identidade da metrópole. São Paulo: Edusp/Hucitec, 1994. 
XAVIER, D. P. Repensando a periferia no período popular da história: o uso do território pelo movimento Hip Hop. Dissertação (Mestrado em Geografia) - Universidade Estadual Paulista, Rio Claro, 2005.

YOSHINAGA, G. K. Resistência, arte e política: registro histórico do Rap no Brasil. Projeto Experimental de Conclusão de Curso (Graduação em Comunicação Social/Habilitação em Jornalismo) - Universidade Estadual Paulista, Bauru, 2001.

\section{Discografia}

CA.GÊ.BE. Lado Beco. Equilíbrio, 2006.

CONSCIÊnCIA humanA. Agonia do Morro. Zambia, s/d.

DA GANG. 0 respeito cabe em qualquer lugar. Grafitte Music/Estúdio Afros Produções, 2005.

DEXTER. Exilado sim, preso não. Porte Ilegal/Atração, 2005.

FACÇÃO CENTRAL. Juventude de atitude. Rhythm and Blues, 1995.

KLJAY. KLJay na batida. Equilíbrio, 1998.

NÚCLEO CULTURAL FORÇA ATIVA. Rimar para a prevenção. (Projeto subsidiado por GOGEST SMS \& DST/AIDS/ Secretaria de Saúde do Município de São Paulo, 2004)

RACIONAIS MC'S. Nada como um dia após o outro dia. Cosa Nostra, 2002.

RAPPER PIRATA. Triunfo. Estúdio Atêlie, 2004.

\section{Outras fontes}

DJ XDEE. Entrevista cedida a Carin Carrer Gomes. São Paulo, 17 jun. 2007.

RAPPER PIRATA. Entrevista cedida a Carin Carrer Gomes. São Paulo, 14 jul. 2007.

Encontros semanais do Fórum de Hip Hop e o Poder Público Municipal, abr. 2006/abr. 2007. Coordenadoria de Juventude pela Secretaria de Participação e Parceria de Prefeitura Municipal de São Paulo.

BROWN, M. (Dir.). História. In: 1000 trutas 1000 tretas (DVD). Racionais MC'S (2005). Cosa Nostra, 2007.

BRITO, G. A periferia grita e os jornais não contam. Vídeo-documentário para Conclusão de Curso (Jornalismo) - Universidade Cidade de São Paulo, 2006. 